\title{
Inscripción, prescripción, ex-cripción. Nancy ante la ley
}

\author{
Inscription, Prescription, Ex-cription. \\ Nancy Facing the Law \\ Jordi Massó CASTILLA \\ Universidad Complutense de Madrid \\ jsmasso@ucm.es
}

Recibido: 20/07/2013

Aceptado: 30/05/2014

\section{Resumen}

Este artículo confronta las lecturas del relato de Kafka En la colonia penitenciaria a cargo de los filósofos Jean-Luc Nancy y Jean-François Lyotard. Este último se ha ocupado detenidamente de esa narración por cuanto ilustra lo que él entiende por "lo intratable", esto es, la prescripción que resiste a toda ley y que tiene que ver con el cuerpo de la aisthesis. La prescripción no sería otra cosa que el sacrificio que se le impone a la estética cuando se la subordina a la ética o a la política, y de ahí la tarea que el arte tiene en la obra de Lyotard de dar testimonio de lo irrepresentable. A esta postura estética Nancy opone la suya, basada como la de Lyotard en una herencia de lo sublime kantiano. Lo que las diferencia es que para Nancy los cuerpos -la estéticano los prescribe la ley, sino que aquéllos son, ante todo, ex-critos. Ex-cripción, pues, frente a prescripción, o lo que es lo mismo, dos formas diferentes de pensar la relación entre ética y estética.

Palabras clave: ética, estética, ley, sublime.

\begin{abstract}
This article confronts the readings of Kafka's story In the Penal Colony by philosophers Jean-Luc Nancy and Jean-François Lyotard. The latter has analyzed it carefully due to that story illustrates his idea of "the untreatable", that is, the pre-
\end{abstract}


scription that resists Law and which has to do with the body of aisthesis. The prescription would be the sacrifice suffered by Aesthetics when it is subordinated to Ethics or Politics, and hence the task that Art has in Lyotard's work: to bear witness to the unrepresentable. Nancy opposes another Aesthetics, based like Lyotard's one on a heritage of the Kantian sublime. The difference between both ideas is that for Nancy bodies - that is, Aesthetics- are not prescribed by Law: they are primarily excribed. Ex-cription compared to prescription, or what is the same, two different ways of thinking about the relationship between Ethics and Aesthetics.

Keywords: ethics, aesthetics, law, sublime.

\section{Introducción}

Nancy ante la ley. El subtítulo de este trabajo merece una explicación y una excusa por su fortuna al encerrar una simpleza, una exageración y una mentira. Una simpleza, pues parece que lo que se va a presentar es una especie de visión de conjunto de la postura de Jean-Luc Nancy ante la ley (o sea, sus pensamientos acerca de los códigos jurídicos, las normas y obligaciones, pero también sobre el derecho y la justicia). Es obvio que una indagación semejante precisaría de un espacio mucho mayor que el que proporciona un artículo académico al uso. En su lugar, me conformaré con bosquejar alguna vía por la que "penetrar" (término que remite inevitablemente al vocabulario conceptual de $\mathrm{Nancy}^{1}$ ) en las reflexiones que este filósofo dedica a estas cuestiones. Valgan, pues, estas palabras, pese a su simpleza, como título o, por introducir desde ya una palabra sobre la que pivotará nuestra reflexión, como prescripción (del latín praescribere, escribir al inicio o titular).

En segundo lugar, Nancy ante la ley es una exageración. No es mi deseo el de colocar a este "adorable" (nuevo vocablo nancyniano), de quien, como dijera Badiou, nadie puede hablar $\mathrm{mal}^{2}$, en la tesitura de aquel campesino que aguarda pacientemente año tras año ante unas puertas, las de la ley, que no se abrirán jamás. No puedo hacerlo, además, porque como veremos, y siguiendo siempre al propio Nancy, ese lugar, situado frente a la ley, no existe. Todo lo más, habría un situarse en el umbral, en el borde que limita, sin cerrarlo, el ámbito de la ley. Doble motivo, pues, por el que, pese a lo que el subtítulo parece asegurar, no podemos llevar a Nancy ante la ley sino, como mucho, intentar tocar con él, con su pensamiento, el problema filosófico del juicio, en concreto el abierto por el juicio kantiano sobre lo sublime.

${ }^{1}$ Cf. J.-L. Nancy, Hegel. L'inquiétude du négatif, París, Hachette, 1997, pp. 22 y 25; J.-L. Nancy, L'Adoration, París, Galilée, 2010, p. 9.

${ }^{2}$ A. Badiou, "L'offrande réservée", en F. Guibal y J-C. Martin (eds.), Sens en tous sens, París, Galilée, 2004, pp. 13-24, aquí p. 15. (La traducción de las obras citadas es nuestra). 
Por último, el encabezado de este artículo, para qué andar con rodeos, una mentira. Nancy ante la ley remite inevitablemente a ese célebre relato de Kafka que acabo de mencionar y que tanto juego ha dado en algunos filósofos franceses a los que Nancy conoce muy bien, como Derrida o Deleuze. No obstante, apenas mencionaré esta narración kafkiana. Prescindiré, pues, de Ante la ley para centrarme, en cambio, en otra muy vinculada a ella, como es La colonia penitenciaria. Mejor dicho, el centro de atención será el comentario que Lyotard hizo de este texto al que ningún calificativo, ningún adjetivo, hacen justicia.

Hasta aquí la introducción a este artículo. Lo único que pretendía este exergo era adelantarse a una posible -y acertada- crítica que censurase esta presentación tachándola de "simple, exagerada y falsa". En realidad, este gesto buscaba, además, introducir una frase que se encuentra en Corpus y que es la que ha dado pie a todas estas reflexiones. Dice así:

"Pero no se trata en absoluto de especular con los límites, y de evocar no se sabe qué trazos que vendrían a inscribirse sobre los cuerpos, o qué cuerpos improbables que vendrían a entretejerse con las letras. La escritura toca los cuerpos según el límite absoluto que separa el sentido de una, de la piel y los nervios de los otros. No pasa nada y es ahí en donde toca. (Detesto la historia kafkiana de La colonia penitenciaria, falsa, fácil y grandilocuente de un extremo a otro)"3.

Falsa, fácil y grandilocuente. O, por emplear como sinónimos los adjetivos antes destacados: mentirosa, simple y exagerada. ¿Por qué despacha Nancy apenas con estas palabras, escasas y tajantes, un relato que gira en torno a la ley, a la escritura y el cuerpo? ¿Por qué el máximo pensador del tacto, como tan acertadamente lo denominó Derrida ${ }^{4}$, obvia una historia acerca de un tocar los cuerpos que los "escribe", torturándolos, hasta conseguir su muerte? Y, sobre todo, ¿hay algo que subyace al mero rechazo "estético" del texto kafkiano?

Probablemente todo lector de Nancy convendrá en que estas preguntas no podrían ser más pertinentes y, sin embargo, difíciles de contestar. Tal vez porque la respuesta hay que buscarla en otro texto de otro autor: el comentario que Lyotard nos dejó de $L a$ colonia penitenciaria, titulado "La prescripción”. Como trataré de demostrar, es allí en donde se comprueba que la despectiva frase de Nancy es algo más que un juicio estético (me gusta, no me gusta; lo adoro, lo detesto). En ella está condensado, o al menos apuntado, su pensamiento estético, como lo está en "La prescripción" el del propio

\footnotetext{
${ }^{3}$ J-L. Nancy, Corpus, París, Métailié, 2006, p. 13. (Corpus, trad. de Patricio Bulnes, Madrid, Arena Libros, 2003).

${ }^{4}$ Cf. J. Derrida, Le toucher, Jean-Luc Nancy, París, Galilée, 2000. (El tocar, trad. de Irene Agoff, Buenos Aires, Amorrortu, 2011).
} 
Lyotard, lo que invita a confrontar ambas lecturas del relato de Kafka para comprender mejor el "diferendo" existente entre las filosofías de uno y otro, lo que equivale a decir entre dos pensamientos que piensan de manera distinta el "fin del arte" o el "fin de la estética" partiendo de una interpretación diferente, que no opuesta, de lo sublime kantiano. Para ello expondré en tres apartados adónde conduce cada uno de los adjetivos empleados por Nancy para caracterizar la narración kafkiana.

\section{2. "Fácil"}

Probablemente este sea el calificativo más ambiguo y el que por ello requiere un mayor esfuerzo interpretativo. Si entendemos por "fácil" que se presta a una lectura evidente, este relato, en efecto, lo es. El comentario que Deleuze y Guattari le dedican apunta a ello:

"La teología negativa o de la ausencia, la trascendencia de la ley, el a-priori de la culpabilidad, son temas recurrentes en muchas interpretaciones de Kafka. Los célebres textos de El proceso (y también de La colonia penitenciaria, de La muralla china) presentan la ley como pura forma vacía y sin contenido, cuyo objeto permanece incognoscible: la ley no puede enunciarse más que en una sentencia y la sentencia no puede aprenderse más que por medio de un castigo. Nadie conoce el interior de la ley. Nadie en la Colonia conoce qué es la ley; y las agujas de la máquina escriben la sentencia sobre el cuerpo del condenado que la desconoce, a la vez que le infligen el suplicio"5.

El relato, recordémoslo, narra la llegada de un visitante a una colonia penitenciaria en donde se encuentra con un oficial que le describe el funcionamiento de una máquina con la que allí se imparte justicia: quienes cometen un delito son condenados a ser torturados por este aparato mediante la inscripción sobre sus cuerpos, con afiladas agujas, de la sentencia condenatoria hasta que tras horas de agonía, justo cuando acaban por entender lo que dice ese edicto, mueren. "La violencia y la simple claridad del texto de Kafka no requieren, como es habitual, comentario alguno", señala Lyotard ${ }^{6}$. Pero, añade, si se aventura a glosarlo es porque se presta a ilustrar lo que él entendía por "lo intratable", esto es, "lo que resiste a toda ley, [y] es también una condición absoluta de la moral". En efecto, según Lyotard La colonia penitenciaria expone con nitidez el diferendo existente entre la estética y la ética, entre el cuerpo y la ley. De las dos, la primera tiene una cierta primacía, aunque sólo sea temporal:

\footnotetext{
${ }^{5}$ G. Deleuze y F. Guattari, Kafka. Pour une littérature mineure, París, Minuit, 2013 (1975), p. 79. (Kafka: por una literatura menor, trad. de Jorge Aguilar, México, Era, 2001).

${ }^{6}$ J-F. Lyotard, "La prescription", en Rue Descartes 1-2, 1991, pp. 239-254. (Lecturas de infancia, traducción de Irene Agoff, Buenos Aires, Eudeba, 1997).
} 


\begin{abstract}
"Ser estéticamente (en el sentido de la primera Crítica kantiana) es estar-ahí, aquí y ahora, expuesto en el espacio-tiempo y al espacio-tiempo de algo que toca antes de todo concepto e incluso de toda representación. Este antes, evidentemente, no lo conocemos, pues está antes de que estemos ahí. Es como el nacimiento y la infancia, que están antes de que estemos ahí. El ahí en cuestión se llama cuerpo"7.
\end{abstract}

La estética, añade Lyotard, sería ese primer toque que nos toca antes de que podamos reconocernos como estando o siendo ahí. O, traducido en términos kantianos, el juego de las facultades comienza por la sensibilidad, que actúa antes de que hagan su aparición la imaginación y el entendimiento.

Estamos situados, pues, en medio de un conflicto entre facultades, y hay una, la sensibilidad, que osa erigirse en instancia primaria e imprescindible para que después, y sólo después, puedan intervenir las otras. La osadía la paga cara: "para la ley, el cuerpo es un exceso", un conjunto disperso de impresiones y sensaciones al que ella debe dar forma, "meter en cintura", como se diría coloquialmente. Pero el cuerpo, el del condenado, se resiste hasta donde puede: "la aisthesis inmemorial de la que el cuerpo extrae su resistencia furibunda a toda acusación, a todo juicio, es, por decirlo así, reducida"9. Terrible lección la que nos enseña Kafka: la justicia sólo se efectúa cuando se ejecuta, ley mediante, sobre el cuerpo de la víctima (que, recordémoslo, desconoce cuál es su culpa). Dicho con otros términos, juzgamos cuando se impone la ley -cuando regula o esquematiza- a la pluralidad de casos que se presentan en la aisthesis. La ley, concluye Lyotard, "no puede ser justa sin ser cruel"10.

Conflicto, acabamos de decir, entre facultades que nos traslada a esa otra disputa que dentro de la filosofía libran la ética, la ontología, la política o la estética, y en la que Lyotard mantiene tanto la irreductibilidad de cada uno de estos "juegos de lenguaje", como la defensa de que la imposición de unos sobre otros no anula su diferendo, sino que produce la injusticia $[\text { le tort }]^{11}$; la misma establecida por el mandato de la ley, su prescripción, que obliga, sujetándonos (o sea, subjetivándonos), a juzgar.

Sin embargo, todo esto podría ser demasiado fácil. Al menos, Nancy se empeña en complicar la cuestión haciendo del cuerpo -de la aisthesis- no el soporte sobre el que se inscribe la ley, sino su propia escritura: la ex-critura:

"El modelo del corpus es el Corpus Juris, colección o recopilación de las Instituciones, Digestos y otros Códices de artículos del derecho romano. No es ni un caos, ni

\footnotetext{
${ }^{7}$ Ibidem, p. 246.

${ }^{8}$ Ibidem, p. 242.

${ }^{9}$ Ibidem, p. 246.

${ }^{10}$ Ibidem, p. 248.

${ }^{11}$ Cf. J-F. Lyotard, Le différend, París, Minuit, 1987. (El diferendo, trad. de Alberto Bixio, Barcelona, Gedisa, 1988).
} 
un organismo: el corpus se mantiene, no precisamente entre ambos, sino más bien en otro lugar. [...] El corpus obedece a la regla que va de caso en caso, continuidad discreta del principio y de la excepción, de la exigencia y de la derogación. La jurisdicción consiste menos en enunciar lo absoluto del Derecho, en desarrollar sus razones, que en decir lo que puede ser el derecho aquí, en este punto, ahora, en este caso, en este lugar. [...] Aquí, la ontología es modal -o modificable o modificadora. De manera esencial, completa y exclusiva. Y es de eso de lo que un corpus es escritura"12.

Según esto, lo que prescribe la ley, su palabra, la jurisdicción, no puede ser una legalidad universal en la que subsumir todos y cada uno de los casos. No otra cosa, como hemos visto, sostiene Lyotard. Ahora bien, el giro que lleva a cabo Nancy consiste en hacer que la ley sea el enunciado que profiere la boca de un cuerpo empeñado en hallar una justicia "sin medida común"13, una justicia "en singular plural"14. Con esto, las dificultades no han hecho sino comenzar. Pero ya estábamos advertidos de que la cuestión que nos ocupa es cualquier cosa menos fácil.

\section{3. "Falsa"}

Fijémonos en esa boca, presente en tantos textos de Nancy ${ }^{15}$. Prestemos atención a lo que va a decir, mantengámonos a la escucha porque ella, ahora ataviada con una toga, se dispone a emitir su veredicto, esto es, etimológicamente su "dicho verdadero". La finalidad del juicio, parece, no podría ser entonces otra que la de enunciar la verdad, o, parafraseando a Nancy, la Verdad diciéndose a sí misma autotélicamente. Yo, la Verdad, hablo. Para ello deberá tener siempre a mano un código preestablecido -pre-escrito- con el que y desde el que juzgar; lo que, como Derrida enseñó, acaba por producir una justicia sometida al cálculo que es la ley, siendo de esta manera anulada. Nancy detecta en Lyotard un afán por evitar que la justicia tenga que decir la ${ }^{l e y}{ }^{16}$, pues si lo hiciera la pluralidad irreductible de los juegos de lenguaje - o, por emplear otra idea cara a Nancy, los singulares plurales que ellos son, pero también

\footnotetext{
${ }^{12}$ J-L. Nancy, Corpus, op. cit., p. 48.

${ }^{13}$ Habría que recordar, en este punto, los análisis que Derrida hace en Force de loi (París, Galilée, 1994) y en "Prejugés. Devant la loi" (en J-F. Lyotard et. al., La faculté de juger, Minuit, París, 1985, pp. 87-139) de la justicia y del derecho. (Fuerza de ley, trad. de Adolfo Barberá y Patricio Peñalver, Madrid, Tecnos, 2008; Prejuzgados. Ante la ley, trad. de Fernando Rampérez y Jordi Massó, Madrid, Avarigani, 2011).

${ }^{14} \mathrm{~J}-\mathrm{L}$. Nancy, "Dies Illa. D'une fin à l'infini, ou de la création”, en D. Lyotard, J-C. Milner y G. Sfez (eds.), Jean-François Lyotard, l'exercice du différend, París, PUF, 2001, pp. 77-99, aquí p. 82.

${ }^{15}$ Remitimos al trabajo en el que por primera vez aparece este conceptualizada la "boca": J.-L. Nancy, Ego sum, París, Flammarion, 1979, en especial las pp. 36, 126, 157 y 162.

${ }^{16}$ Cf. J-L. Nancy, “Dies Irae”, en J-F. Lyotard et. al., La faculté de juger, op. cit., p. 13.
} 
la estética, la ética, la ontología...-, quedaría automáticamente anulada: así es como nace el terror. Sin embargo, como acabamos de ver, para Lyotard es propio de la justicia actuar con crueldad al imponer la ley (la ética, la norma) al cuerpo (la estética). La ley acaba siempre dominando. Y ella tiene por único contenido una prescripción: hay que juzgar.

Ahora bien, no todos los juicios son iguales. Los hay que se limitan a subsumir "bajo leyes universales transcendentales que da el entendimiento"17, y los hay que se encuentran con un particular para el que deben encontrar un universal. Unos y otros, determinantes y reflexivos, son como es sabido, los pilares de la tercera Crítica kantiana. Pues bien, lo que Nancy, desde mi punto de vista, parece reprochar a Lyotard es que su concepción de la ley sólo parece contemplar una aplicación de la misma consistente en imponer una legalidad a una multiplicidad, lo que sólo se consigue ejerciendo la misma crueldad de la que hace gala el oficial (una crueldad no reñida con una cierta asepsia profesional) y que es propia de la ley por la que se rige la colonia penitenciaria. Ni rastro, pues, del juicio reflexionante ni de su potencia para inventar leyes. Sin ésta, la ética, la moral, se imponen irremisiblemente a la estética, subordinando el arte, por ejemplo, al mandato de ajustarse a un ideal de belleza y/o de verdad. No otra cosa es lo que experimenta el cuerpo cuando la ley graba sobre la piel una sentencia, sin duda ilegible, pero conforme o adecuada a la ley: verdadera. Para colmo de males, tanto en el relato kafkiano como en su lectura a cargo de Lyotard, la política parece asumir el rol de mantenimiento de esta situación entre litigantes que en modo alguno están en las mismas condiciones.

La salida a este conflicto, a esta "sinrazón", como suele traducirse el tort lyotardiano, pasa, para Nancy, por recuperar este carácter creativo que tiene, o debe tener, el juicio, y que no coincide, al menos en su mayor parte, con el reflexivo kantiano: "en este punto, se hace sin duda necesario pensar que allí donde Kant concibe el empleo reflexivo siguiendo el régimen de una prudencia que desconfía de la Schwärmerei metafísica, nosotros debemos pensarlo en el régimen de una invención activa y creadora de los fines" 18 . Con esto se toma distancia respecto a un juicio que tuviera por fin una Idea como la de la libertad, y que por ello subordinara el arte a esta finalidad. El modelo para este tipo de juicio lo toma Nancy de lo sublime kantiano (que es, hay que insistir en ello, un sentimiento y no la propiedad de un objeto) que remite, según Lyotard -y en esto coincide con él Nancy- a una Idea de infinitud. Será en el momento en que haya que decidir lo que el arte puede y debe hacer con este infinito, por definición irrepresentable, cuando resurjan las diferencias entre los dos filósofos franceses.

${ }^{17}$ J-L. Nancy, “Dies Illa”, op. cit., p. 90.

${ }^{18}$ Ibidem, p. 83. 
Enseguida iremos a ello. Antes es preciso regresar al acontecimiento de la creación propiciado por el juicio acerca de lo sublime, pues sólo él permite la superación de la onto-teología que hace del arte una manifestación de la Idea, poniendo en funcionamiento otra máquina, la de la vieja mimesis, culpable, en último término, de que hasta hace bien poco se juzgasen las obras en términos de verdad o adecuación respecto a un modelo que se trataría de representar. El nuevo juicio no esquematiza: inventa sus esquemas; no subsume lo particular en lo universal: muestra lo singular plural de cada caso; por último, no produce [poiesis] sus fines: los crea modificándose él mismo en el proceso [praxis]. Y el juicio, al igual que el cuerpo, se presenta unido a una imaginación que no lo produce en un cadena tan causal como teleológica, sino que los expone a ambos como imágenes: "la imaginación está por tanto destinada al más allá de la imagen, lo cual no es una presencia (o una ausencia) primordial (o última) que las imágenes representarían o de las que las imágenes presentarían que ella no es (re)presentable"19.

El oficial de la colonia toma el cuerpo de la víctima como el soporte en el que inscribe el dictamen de la ley: la estética se ve así obligada a adoptar las finalidades que le impone esta ley dictada por diversas instancias: la ética, la política, la epistemología... la onto-teología. En el caso de las artes, tal fin no es otro que el de la representación de la Idea (de Belleza, de Libertad...), empresa a la que Hegel le puso su punto y final cuando decretó el fin del arte. Ahora comprendemos mejor cuando Nancy tacha de "falsa" a esta historia kafkiana, articulada a partir de una subyugación de la estética a la ética o a la moral, como apunta Lyotard. Es necesario, pues, pensar otra forma de creación (para lo que nos ocupa, de juicio, pero no sólo de esto) que se sustraiga a la posibilidad de supeditarse -"suturarse", diría Badiou- a una prescripción heterónoma. La ley debe enunciarse en cada caso, cada vez única, pues, como vimos antes, para Nancy "la jurisdicción consiste menos en enunciar lo absoluto del Derecho, en desarrollar sus razones, que en decir lo que puede ser el derecho aquí, en este punto, ahora, en este caso, en este lugar". La ley, por consiguiente, como el hic et nunc de la decisión que se pone en marcha cada vez que su boca se abre para expresar ese difícil, dificilísimo, equilibro entre la universalidad y la particularidad, entre lo singular y lo plural, que se ven obligados a buscar quienes, como el monarca hegeliano analizado por $\mathrm{Nancy}^{20}$, están en posesión de una soberanía que imparten dentro de su jurisdicción.

Trasladado, una vez más, al constructo kantiano, lo anterior nos sitúa ante ese momento en el que la imaginación se revela incapaz de seguir actuando de mensajera

${ }^{19}$ J-L. Nancy, “L'offrande sublime”, en J-L. Nancy (ed.), Du sublime, París, Belin, 1988, pp. 37 75 , aquí p. 61.

${ }^{20}$ Cf. J-L. Nancy, "La jurisdiction du monarque hégélien", en P. Lacoue-Labarthe y J-L. Nancy (eds.), Rejouer le politique, París, Galilée, 1981, pp. 51-90. 
entre facultades ${ }^{21}$, llevando al entendimiento lo aprehendido por la sensibilidad; o, por emplear otras palabras, produciendo imágenes que representan un objeto ausente. Es el instante en el que "la imaginación, compelida a presentar sensiblemente algo que re-presentaría lo Absoluto, no sólo no lo conseguiría, sino que ella misma se "hundiría"" 22 . En este punto, se habrá adivinado, está naciendo lo sublime.

\section{4. "Grandilocuente"}

\section{Leamos a Nancy:}

"El juicio acerca de lo sublime no es sino el juicio de que debo juzgar. Por eso lo sublime no es tan "sublime", quiero decir, tan grandilocuente, como lo presenta la palabrería pre-romántica de lo "sublime de la naturaleza" [...] Lo sublime es sobrio. [...] La simplicidad corresponde al mandato "más sublime" de la Biblia, la prohibición de representar a Dios. Lo sublime de la simplicidad consiste en no representar, es decir, conforme a todo el rigor del término en la ontología de la subjetividad, en no presentarnos lo incondicionado, sino en juzgar -en juzgar con simplicidad-, pues el libre juicio es él mismo lo incondicionado que nos obliga. La presentación de lo incondicionado sería la supresión del juicio -y la supresión de lo incondicionado-" 23 .

Tanto el relato de Kafka como la lectura pre-romántica de lo sublime, son grandilocuentes, es decir, hablan demasiado elocuentemente, dicen más de lo que deben, o mejor, de lo que pueden. El primero, por su pretensión de que la ley puede someter a los cuerpos a su antojo para que se haga (su) justicia; la segunda, porque ve en los objetos sublimes -aún no ha estallado la revolución copernicana de Kant- el signo de una entidad trascendental como es la naturaleza. En ambos casos, asistimos a una disolución del dominio de la estética, bien por estar atado a la ética, bien por estar sometido al mandato de representar algo situado epekenia tes ousias. Frente a esto, Nancy nos recuerda que para Kant lo sublime reside, a pesar de su nombre, en la sencillez de una presentación o, en términos de Lyotard, de una enunciación o "fraseo". Y no es la libertad o la verdad los que se presentan, sino que es el propio gesto o acto de presentación en "su estado naciente" el que se muestra (se ofrece, dirá Nancy; a ser tocado, convenimos con él).

\footnotetext{
${ }^{21}$ Lo que nos conduciría al problema de la hermenéutica tal y como ha sido pensado por Nancy, fundamentalmente en Le partage des voix (París, Galilée, 1982). (La partición de las voces, trad. de Cristina Rodríguez y Jordi Massó, Madrid, Avarigani, 2013).

${ }^{22}$ J-F. Lyotard, Heidegger et "les juifs", París, Galilée, 1988, p. 59. (Heidegger y los judíos, trad. de Alejandro Kaufman y Verónica Weiss, Buenos Aires, La Marca, 1995).

${ }^{23}$ J-L. Nancy, "Dies Irae", op. cit., pp. 47-48.
} 
Tanto Nancy como Lyotard coinciden en considerar decisivo el momento en el que el arte se libera de la prescripción representativa para obedecer al único mandato del juicio: debes juzgar, esto es, crear la ley o el esquema, toda vez que éste ya no puede enlazar con el entendimiento. Tampoco puede ya entregarse al gozo autocomplaciente que produce la contemplación de lo bello, pues como es sabido en lo sublime se presenta una combinación de placer y temor: "el tacto produce alegría y dolor", afirma Nancy en Corpus $^{24}$. Ante ese otro disfrute proporcionado por lo bello, el sujeto de la ontología de la subjetividad de la que hablaba Nancy siente un profundo reconocimiento: gracias a él reconoce su identidad. En cambio el sentimiento que suscita lo sublime se traduce en un entusiasmo que consigue que el sujeto se emocione. Y es precisamente por medio de esta emoción como el sentimiento de lo sublime "hace vacilar la lógica filosófica de la estética"25.

Lo sublime ha sido entonces lo que ha permitido superar un tipo de estética caracterizado por su simpleza -que no sobriedad-, su grandilocuencia y su falsedad o, mejor dicho, su dependencia de la lógica representativa que concibe la verdad en términos de adequatio. De paso, ha contribuido a cuestionar el sujeto de la metafísica y a proponer su sustitución, en el caso de Lyotard, por un sujeto en estado naciente: el sensus communis. No es éste el lugar en el que desarrollar como sería conveniente el distinto tratamiento que ambos filósofos hacen de este motivo kantiano dependiente, es cierto, de la analítica de lo bello y no de la de lo sublime. No obstante, debe al menos quedar constancia de la posible conexión que puede haber en la obra de Nancy entre ambos silencios: por un lado, la casi total negativa a comentar el relato de Kafka, tan admirado en cambio por Lyotard; por otro, la escasa atención que presta al sensus communis kantiano que comparte muchos rasgos de la "communauté desœuvrée", lo que por sí solo parecería justificar al menos un comentario.

\section{Inscripción, prescripción, ex-cripción}

Llegamos así al final de esta reflexión y, con ella, al punto en que los caminos que emprenden Nancy y Lyotard en su lectura de lo sublime kantiano se separan irremediablemente formando un diferendo. En cierto modo, la postura que cada uno de ellos asume frente a la Estética parte de la constatación de las dificultades y desafíos que para el pensamiento sobre el arte encarna lo sublime. Lyotard, como se ha visto, considera que en este punto se produce un cambio decisivo en el ámbito estético. El arte ya no puede ser pensado en términos de semejanza, de representación de un original, pues precisamente esto último, llámese "modelo", "Idea", "Belleza"..., es irrepresentable. Ahora bien, la prescripción obliga, precisamente, a representar esta misma irre-

\footnotetext{
${ }^{24}$ J-L. Nancy, Corpus, op. cit., p. 102.

${ }^{25}$ J-L. Nancy, "L'offrande sublime”, op. cit., p. 63.
} 
presentabilidad. Persistiría de esta forma en Lyotard la imposición al arte de una ley: mostrar "lo intratable", inscribirlo desvinculándolo de cualquier Estética, sacrificada, como el cuerpo de los delincuentes de la colonia, en aras a la nueva ley ("Sé justo"):

"Esta incapacidad [de la imaginación para producir formas para presentar lo absoluto] inaugura y escande el fin del arte, no como arte, sino como forma bella. Si el arte persiste, y lo hace, será otro distinto, al margen del gusto y dedicado a proporcionar esta nada, esta afección que nada debe a lo sensible y todo a un secreto insensible. [...] Es de su defección de lo que lo sublime es emoción, defección que no puede hacerse sentir mediante la aisthesis, sino solamente por pathos. Una posibilidad insensible, una anestesia por consiguiente pero que deja al alma ofrecida a una afección más antigua que los dones de la naturaleza y que ninguna imitación mediante la forma y la figura igualará jamás"26.

La, llamémosla así, "Estética anestésica” de Lyotard renuncia, pues, a lo corporal, a lo propiamente "estético" para poder vincular el arte con un imperativo ético: representar lo irrepresentable. El pensamiento de este filósofo sigue entonces anclado en ese conflicto entre facultades señalado por Kant y que, según parecía, quedaba superado por la constatación de lo sublime. No es posible, por tanto, superar el diferendo entre ética y estética, ya que cualquier forma de acuerdo posible entre ambas pasa por el dominio de una sobre otra: esto es, por que una prescriba a la otra su forma de actuar.

Frente a esto, Nancy recuerda que en la estética sigue imperando un mandato. La única ley que el arte debe obedecer no es la de sujetarse a la ética, a la política o a cualquier otra finalidad interesada; este dominio es, o debería ser, el del puro desinterés. De ahí que la ley sólo prescriba al arte una cosa: escuchar su llamada, escribir, crear. No pensar en una estética anterior o posterior a la ética, ni en una prescripción en cuanto orden originario que impone una finalidad, sino en el instante en el que ambas, ética y estética se dan simultáneamente porque entre ellas no hay ni preeminencias ni diferendos. Este momento es el de la ex-critura. En este caso el prefijo remite a un espacio exterior y no a un tiempo anterior (pre-scripción) y por tanto fundador: "este "afuera" -completamente excrito en el texto- es la infinita retirada de sentido gracias al a cual cada existencia existe" 27 , señala Nancy en un interesante artículo titulado "L'excrit" compuesto por dos textos breves, uno redactado en 1988 y el otro en 1977. En este último encontramos otra mención al relato de Kafka del que vengo ocupándome. No se trata, ni mucho menos, de un comentario, sino de una alusión que al menos carece del tono despectivo del pasaje citado de Corpus y que pone de relieve cuál es la única ley que los cuerpos, que la estética, pueden cumplir:

\footnotetext{
${ }^{26}$ J-F. Lyotard, Heidegger et "les juifs", op. cit., p. 78.

${ }^{27}$ J-L. Nancy, “L’excrit”, en Poésie 47, 1988, pp. 107-121, aquí p. 120.
} 
"El oficial que maneja la máquina se ejecuta a sí mismo al final de la historia grabando sobre su cuerpo la ley que él mismo ha violado: ¡Sé justo! No obstante, sólo queda la máquina enloquecida para aplicar de forma salvaje la ley -el comunismo y el capitalismo de las máquinas de escribir-. Es, sin embargo, la misma demanda: ¿cómo liberar a todo lo demás del libro?”28.

O lo que es lo mismo, ¿cómo puede escapar la estética de esa ley enloquecida, cruel, que parece encadenarla siempre a una finalidad? Mediante la ex-critura, dice Nancy. Esto es, pensando el arte como la respuesta a una llamada, a una ley, si se prefiere, que sólo pide que aquél -toda vez que lo sublime ha constatado su liberación de cualquier otra finalidad-ex-criba los cuerpos: no que los sacrifique, sino que los sitúe en el horizonte de sentido que ellos mismos crean. En definitiva, que el arte no se subordine a orden alguno, que no obedezca ninguna ley salvo ese imperativo que él mismo inscribe cada vez que crea: mostrarse ex-cribiendo sin obedecer ninguna otra prescripción.

${ }^{28}$ Ibidem, p. 114. 